\title{
The effect of different spectral LED lights on the phenotypic and physiological characteristics of lettuce (Lactuca sativa) at picking stage.
}

\author{
Tao Zhang ${ }^{1}$, Yuanyuan Shi ${ }^{1}$, Yuanyuan Wang${ }^{1}$, Yongpeng Liu ${ }^{1}$, Weixing Zhao ${ }^{2}$, Fengzhi Piao ${ }^{1}$, \\ Zhiqiang Sun ${ }^{1 *}$ \\ ${ }^{1}$ College of Horticulture, Henan Agricultural University, Zhengzhou 450002, China \\ ${ }^{2}$ Institute of Horticulture, Henan Academy of Agricultural Sciences, 116HuayuanRoad, Zhengzhou, China
}

\begin{abstract}
Light plays crucial roles in plant morphological and physiological processes. In this study, lettuce plants ( Lactuca sativa $L$.) were exposed to different spectral LED lights for 16 hd-1 photoperiod under the following eight treatments: white light ( $W$, the control), monochromatic red light (R), monochromatic blue light (B), monochromatic green light (G), monochromatic yellow light (Y), monochromatic purple light $(P)$ and a combination of $R$ and $B$ with $R / B$ ratios of $9 / 1$ and $4 / 1$. Lettuce phenotype and some quality related indices were significantly changed under different LED lights. The vitamin $C$ content of lettuce was increased under most of different light treatments, while the anthocyanin content was significantly increased only under G LED light treatment. In addition, R/B (4/1) increased soluble sugar and protein content and $R$ and $B$ combinations particularly $R / B$ (4/1) improved phenotypic characteristics including plant height, stem diameter, fresh weight above ground, Soil and Plant Analyzer Development (SPAD). These results suggested R/B (4/1) could efficiently improve the lettuce quality which will provide valuable information for optimizing the conditions of lettuce production in the plant factory setting.
\end{abstract}

Keywords: Monochromatic, Photosynthesis, Physiological characteristics, Phenotypic characteristics

Abbreviations:

LED: Light Emitting Diodes; SPAD: Soil and Plant Analyzer Development; TSP: Total Soluble Protein; GS: Glutamate

\section{Introduction}

Light is an important environmental factor and plays key roles in plant growth and morphology [1]. Different light spectrum can produce diverse morphological and physiological responses in plants [2]. The effects of light intensity on plant physiological response were conducted [3,4]. Light-emitting diodes (LEDs) have a long life, high brightness, are environment friendly and their spectrum can be manipulated [5]. Furthermore, LEDs can efficiently promote plant growth and development. Plant morphology and physiology are strongly influenced by light quality, such as colour and wavelength [6]. Red (R) and blue (B) light are both vital wavelengths for plant growth and development. In vegetable plants, including tomato, pepper, lettuce and cucumber, different R: G: B photo flux (PF) ratios have been tested $[7,8]$.

Lettuce (Lactuca sativa) is a major fresh salad food crop with fast growth and high commercial value. Lettuce is flowering plant which is sensitive to light quality, and it is a member of the large Asteraceae family and $[9,10]$ reported that the combination of $\mathrm{B}$ and $\mathrm{R}$ inhibited hypocotyl extension and cotyledon elongation, while other reports showed that the combination of $\mathrm{B}$ and $\mathrm{R}$ increased lettuce dry weight and leaf number $[6,11]$.
Synthase; GOGAT: Glutamine Oxoglutarate Aminotransferase; GDH: Glutamate Dehydrogenase; VC: Vitamin C

Accepted on 25 October, 2017

However, $\mathrm{R}$ treatment alone produced higher dry weight compared with a mixture of $\mathrm{R}$ and $\mathrm{B}$ [12-14]. Cope et al. [8] found that $0.3 \% \mathrm{~B}$ produced longer stem length in lettuce than $92 \%$ B using different B:G:R ratios in lettuce. Wang et al. [2] examined different ratios of LED $\mathrm{R}$ light to $\mathrm{B}$ light on photosynthetic performance by measuring leaf morphology, photosynthetic rate, chlorophyll fluorescence, stomatal development, light response curve, and nitrogen content in lettuce. B light promoted photosynthetic performance or growth by stimulating morphological and physiological responses. Han et al. [15] optimized LED light for lettuce growth to approximately $75^{\circ}$ for accelerating the growth of lettuce.

The aim of this study was to elucidate the effects of different LED wavelengths on plant growth and development in plant factory setting. The yield, quality characteristics, nutritional components, secondary metabolites and antioxidant activity were measured in lettuce grown under different monochromatic LED lights to gain insight into the mechanisms by which LEDs affect lettuce quality and ultimately provide valuable information for producing lettuce in a plant factory setting. 


\section{Materials and methods}

\section{Plant material and treatments}

The loose-headed lettuce variety "United States greatly fastgrowing lettuce" was used in this study. Seeds were germinated on filter paper and placed into polyurethane cubes under dim natural sunlight for $22 \mathrm{~d}$. The seedlings were transplanted into an indoor vertical plant factory system. The plants were subjected to a $16 \mathrm{~h}$ photoperiod of (1) white LED light (W), as control (400-800 nm); (2) P, purple LED light (peak at 430 $\mathrm{nm}$ ); (3) B, blue LED light (peak at $460 \mathrm{~nm}$ ); (4) R, red LED light (peak at $660 \mathrm{~nm}$ ); (5) G, green LED light (peak at 530 $\mathrm{nm}$ ); (6) Y, yellow LED light (peak at $590 \mathrm{~nm}$ ); (7) 9R/1B, $90 \%$ red $+10 \%$ blue LED light; (8) $4 \mathrm{R} / 1 \mathrm{~B}, 80 \%$ red $+20 \%$ blue LED light (ZPDT802-200Zhishengpu Ltd., Zhengzhou, China), and light intensity for all treatment was 150 $\mu \mathrm{mol} \cdot \mathrm{m}^{-2} \cdot \mathrm{s}^{-1}$.

The spectra parameters of the eight LED lights are shown in Figure 1. Photon fluxes were measured below the LED plate $(20 \mathrm{~cm})$ using a spectroradiometer (PAR-NIR, Apogee Instruments Inc, Logan, UT, USA).

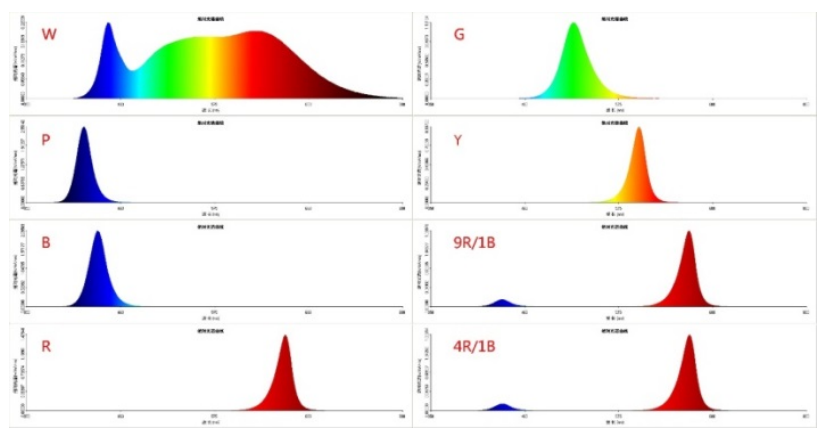

Figure 1. Absolute spectral distribution of different LED lights. Top to bottom: W LED, B LED, R LED, G LED, P LED, Y LED, R/B $(9 / 1)$ and $R / B$ (4/1). $X$ axis indicates the wavelength and $y$ axis indicates the absolute spectral value.

Temperature and relative humidity in the growth room were maintained at 24/18 (day/night) and 48\%-52\%/60\%-70\% (day/ night), respectively. Plants were supplied with a nutritional solution for Japan Yamazaki lettuce: $236 \mathrm{mg} / \mathrm{L}$ $\left(\mathrm{Ca}\left(\mathrm{NO}_{3}\right) 2.4\left(\mathrm{H}_{2} \mathrm{O}\right), 404 \mathrm{mg} / \mathrm{L} \mathrm{KNO}_{3}, 57 \mathrm{mg} / \mathrm{L} \mathrm{NH}_{4} \mathrm{H}_{2} \mathrm{PO}_{4}\right.$, and $123 \mathrm{mg} / \mathrm{L} \mathrm{MgSO}_{4} \cdot 7 \mathrm{H}_{2} \mathrm{O}$ and common microelements 20-40 mg/L EDTA ferric sodium, $2.86 \mathrm{mg} / \mathrm{L}$ boric acid, 2.13 $\mathrm{mg} / \mathrm{L} \quad \mathrm{MnSO}_{4} \cdot 4 \mathrm{H}_{2} \mathrm{O}, \quad 0.22 \mathrm{mg} / \mathrm{L} \quad \mathrm{ZnSO}_{4} \cdot 7 \mathrm{H}_{2} \mathrm{O}, 0.08 \mathrm{mg} /$ $\mathrm{LCuSO}_{4} \cdot 5 \mathrm{H}_{2} \mathrm{O}$ and $0.02 \mathrm{mg} / \mathrm{L}\left(\mathrm{NH}_{4}\right) 6 \mathrm{MO} 7 \mathrm{O} 24 \cdot 4 \mathrm{H}_{2} \mathrm{O} \cdot \mathrm{CO}_{2}$ concentration was maintained at $400 \mu \mathrm{mol} \cdot \mathrm{mol}^{-1}$, electrical conductivity (EC) value and nutrient solution $\mathrm{pH}$ were maintained at $1.2-1.6 \mathrm{~ms} / \mathrm{cm}$ and $6.0-6.9$, respectively. The samples were harvested $35 \mathrm{~d}$ after transplanting.

\section{Phenotypic and physiological parameters measurement}

After treating for 35 days under abovementioned conditions, Plant height was measured using a ruler, stem diameter and leaf thickness were measured using Vernier calipers, SPAD (Soil and Plant Analyzer Development) value was measured by chlorophyll instrument and fresh weight (FW) of above ground material was measured using an analytical balance (YajinAN110, ShangHai China). All experiments were performed with three biological replicates.

Vitamin C (VC) was measured using the 2, 6-D titration method [16]. Anthocyanin and soluble sugar was measured using spectrophotometer $[17,18]$. The amount of total soluble protein (TSP) and glutamate synthase (GS), glutamine synthetase (GOGAT) and glutamate dehydrogenase (GDH) were measured using a kit from Biotechnology Co., Ltd (Suzhou, China).

\section{Statistical analysis}

The data are the average of three replicates \pm standard derivation (SD) for each treatment. The data was calculated by ANOVA using SPSS 20.0. Software Letters in the figures represent statistical significance at $\mathrm{P}<0.05$ level.

\section{Results}

\section{Effect of different spectral LEDs on lettuce phenotype}

The absolute spectrum curve of the eight LED light combinations is shown in Figure 1; W LED (peak wavelength $455 \mathrm{~nm}, 560 \mathrm{~nm}$ ), B LED (peak wavelength $455 \mathrm{~nm}$ ), R LED (peak wavelength $661 \mathrm{~nm}$ ), G LED (peak wavelength $532 \mathrm{~nm}$ ), P LED (peak wavelength $590 \mathrm{~nm}$ ), Y LED (peak wavelength $560 \mathrm{~nm}), \mathrm{R} / \mathrm{B}(9 / 1)$ and R/B (4/1) with two peak wavelengths of $455 \mathrm{~nm}$ and $661 \mathrm{~nm}$, respectively. The growth state of lettuce grown under different spectral LED lights was significantly different (Figure 2).
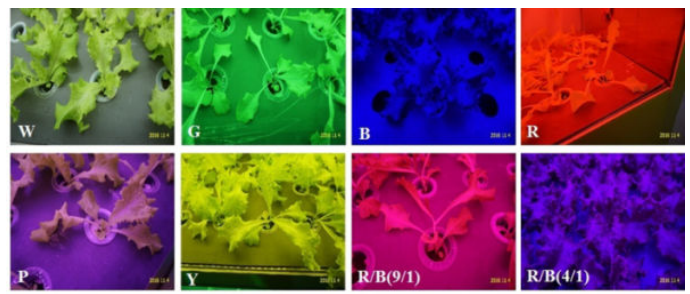

Figure 2. The leaf phenotype of lettuce grown under different spectral LED lights.

The highest length of lettuce was detected under $\mathrm{R}$ light compared with the W light, followed by $\mathrm{G}$ and $\mathrm{R} / \mathrm{B}(9 / 1$ and $4 / 1$ ), while no difference was observed for lettuce grown under $\mathrm{B}, \mathrm{P}$ and $\mathrm{Y}$ lights (Figure 3a). Stem diameter was lower under $G$ and $Y$, while other lights had no significant effect on stem diameter compared with that of white light (Figure 3b). Leaf thickness was not significantly different under other lights except for $G$ light (Figure 3c). Fresh weight of the above ground plant was significantly lower under $G$ and $Y$ lights, other lights had no differences (Figure 3d). SPAD value increased under $\mathrm{B}$ and $\mathrm{R} / \mathrm{B}(4 / 1)$, but decreased under $\mathrm{G}, \mathrm{R}, \mathrm{Y}$, $\mathrm{R} / \mathrm{B}(9 / 1)$ compared with that under white light (Figure 3e). Number of leaves was lower under all other lights compared with that under white light (Figure 3f). 


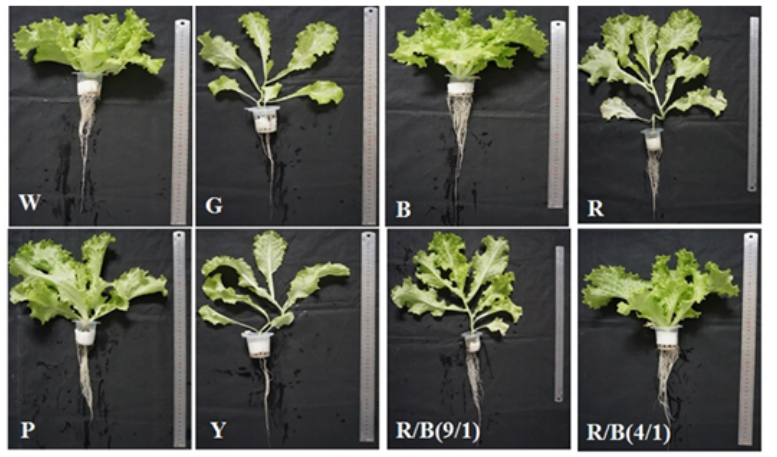

(a) (b)

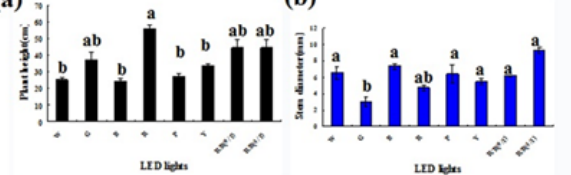

(c)

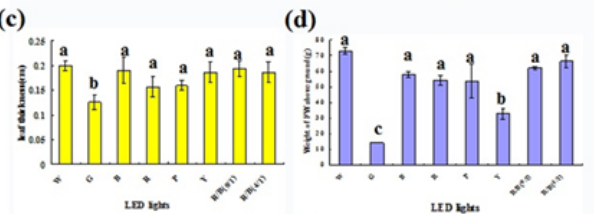

(e)

(f)

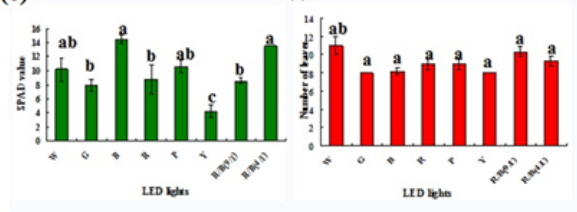

Figure 3. The leaf and root phenotype of lettuce grown under different spectral LED lights Compared with the $\mathrm{W}$ light, Lettuce height was highest under R light, followed by $G$ and R/B (9/1 and 4/1), Stem diameter was lower under G and Y, while other lights had no significant effect on stem diameter (Figure 3b). Leaf thickness was not significantly different under other lights except for $G$ light (Figure $3 \mathrm{c})$. Fresh weight of the above ground plant was significantly lower under $\mathrm{G}$ and $\mathrm{Y}$ lights, other lights had no differences (Figure 3d). SPAD value increased under B and R/B (4/1), but decreased under $G$, R, Y, R/B (9/1) (Figure 3e). Number of leaves was lower under all other lights (Figure $3 \mathrm{f}$ ).

\section{Effect of different spectral LED lights on the content of anthocyanin and vitamin $C$}

The content of anthocyanin and vitamin $\mathrm{C}$ was investigated for the effect of eight different colour LED lights: white (W), green $(\mathrm{G})$, blue (B), red (R), purple (P), yellow (Y), R/B (9/1) and $\mathrm{R} / \mathrm{B}(4 / 1)$. Compared with the $\mathrm{W}$ treatment, the content of anthocyanin was significantly different $(p<0.05)$ after $G, B, P$, $\mathrm{Y}$ and $\mathrm{R} / \mathrm{B}=9 / 1$ treatments; G LED light treatment significantly increased anthocyanin content (Figure 4), while, B, P, Y and R/B (9/1) treatments significantly decreased anthocyanin content. Compared with the $\mathrm{W}$ treatment, G, Y, P, R/B (4/1) and $\mathrm{R} / \mathrm{B}(9 / 1)$ treatments significantly increased $\mathrm{VC}$ content $(\mathrm{p}<0.05)$ (Figure 4).

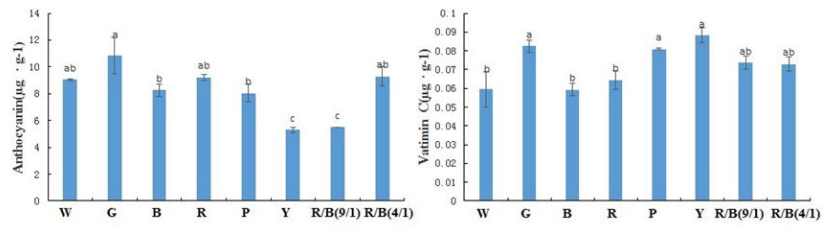

Figure 4. Anthocyanin and vitamin $\mathrm{C}$ content of lettuce grown under different LED lights Compared with the white control, the content of anthocyanin was significantly different $(\mathrm{p}<0.05)$ after $\mathrm{G}, \mathrm{B}, \mathrm{P}, \mathrm{Y}$ and $R / B=9 / 1$ treatments; $G$ treatment significantly increased anthocyanin content, while, B, P, Y and R/B (9/1) treatments significantly decreased anthocyanin content., and G, Y, P, R/B (4/1) and R/B (9/1) treatments significantly increased $\mathrm{VC}$ content $(\mathrm{p}<0.05)$.

\section{Effect of different spectral LED lights on the content of soluble sugar and soluble protein}

Compared with the $\mathrm{W}$ treatment, R, P and R/B (4/1) treatments significantly enhanced the soluble sugar content, especially for the $\mathrm{R}$ treatment which increased soluble sugar content by up to five-fold (Figure 5). Furthermore, B, P, R/B (9/1) and R/B (4/1) LED lights significantly affected soluble protein content; $B$ and $\mathrm{R} / \mathrm{B}(4 / 1)$ lights promoted the biosynthesis of soluble protein, but $\mathrm{P}$ and $\mathrm{R} / \mathrm{B}(9 / 1)$ lights significantly $(\mathrm{p}<0.05)$ decreased soluble protein content compared with the $\mathrm{W}$ treatment (Figure 5).
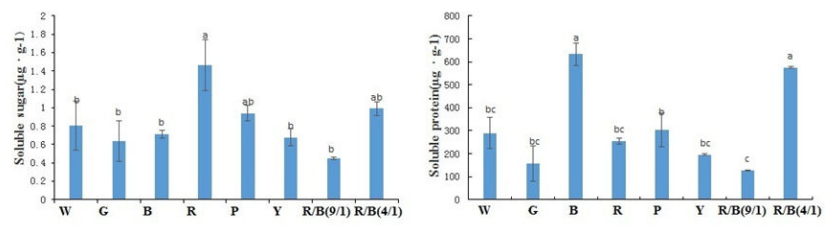

Figure 5. Soluble sugar and soluble protein content of lettuce grown under different LED lights Compared with the white control, R, P and $\mathrm{R} / \mathrm{B}(4 / 1)$ treatments significantly enhanced the soluble sugar content, especially the R treatment, and B, P, R/B (9/1) and R/B (4/1) LED lights significantly affected soluble protein content.

\section{Effect of different spectral LED lights on the activity of enzymes involved in ammonia assimilation}

To investigate the effect of different spectral LED lights on the process of ammonia assimilation, three key enzymes involved in ammonia metabolism, including glutamate synthase (GS), glutamine synthetase (GOGAT) and glutamate dehydrogenase (GDH), were measured after W, G, B, R, P, Y, R/B (9/1) and $\mathrm{R} / \mathrm{B}(4 / 1)$ treatments. The B LED light resulted in a 100 -fold increase in GOGAT activity $(\mathrm{p}<0.05)$ compared with the $\mathrm{W}$ treatment. The G, B, P and R/B (4/1) treatments significantly altered GS activity; $\mathrm{B}$ and $\mathrm{P}$ LED lights increased the activity of GS, while G and R/B (4/1) decreased GS activity compared with the W LED. Only the R/B (4/1) treatment significantly increased the GDH activity (Figure 6). 


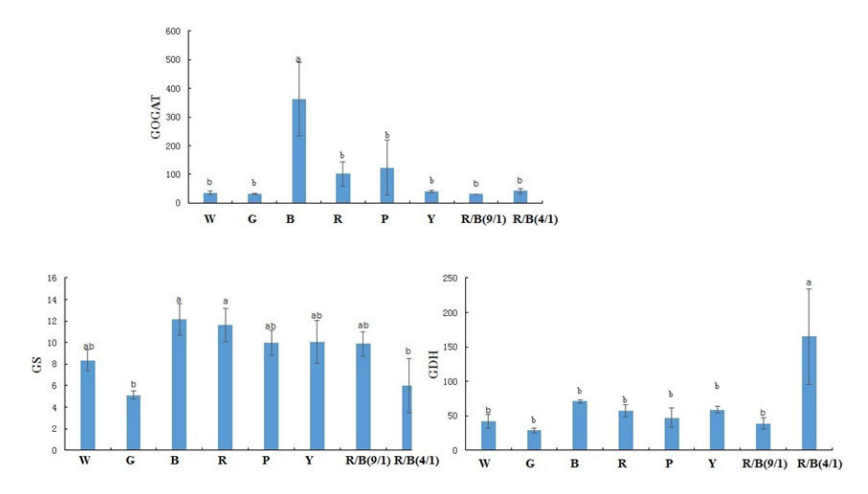

Figure 6. The activity of enzymes involved in ammonia assimilation under different LED lights Compared with the white control, the B LED light resulted in a 100 -fold increase in GOGAT activity $(p<0.05)$. The G, B, P and R/B (4/1) treatments significantly altered GS activity; $B$ and P LED lights increased the activity of GS, while G and R/B (4/1) decreased GS activity. Only the R/B (4/1) treatment significantly increased the GDH activity.

\section{Discussion}

Light influences plant growth and development mainly via photo morphogenetic pigments. These include the red/far-red light absorbing phytochromes and blue/UV light absorbing pigments, which were decided by quality, quantity, direction and duration of light [19]. Plants grown under optimal R and B combination tend to have the highest $\mathrm{Pn}$ and $\mathrm{Chl}$ concentrations, although the optimal $\mathrm{R}$ and $\mathrm{B}$ ratio varies among different plant species [20-24]. In tomato, higher B:R ratios decreased tomato plant height under single source electrical light $[7,14,25]$. In this study, lettuce height was highest when grown under $\mathrm{R}$ light, followed by $\mathrm{G}$ and $\mathrm{R} / \mathrm{B}(9 / 1$ and 4/1) combinations; no difference was observed when grown under $\mathrm{B}, \mathrm{P}$ and $\mathrm{Y}$ LED lights compared with the $\mathrm{W}$ LED.

Oh-Hama and Hase [26] showed that B light is critical to initiate chlorophyll biosynthesis and increasing B photo flux could improve chlorophyll concentration in green algae [27-29]. Additionally, many studies have shown that only B light affects leaf photosynthetic performance including chlorophyll content, chlorophyll $\mathrm{a} / \mathrm{b}$ ratio, chlorophyll $\mathrm{a} / \mathrm{b}-$ binding protein of the PSII system and the electron transport chain [30-32]. To our knowledge, SPAD value was positively related with chlorophyll concentration. In our study, SPAD significantly increased under B and R/B (4/1) lights, however, $\mathrm{B}$ and $\mathrm{Y}$ light significantly repressed chlorophyll content in lettuce. Interestingly, the SPAD value decreased under monochromatic $\mathrm{R}$ and $\mathrm{G}$, but increased when $\mathrm{R}$ and $\mathrm{B}$ were combined. This is consistent with Tripathy and Brown [33] who showed that $\mathrm{B}$ and $\mathrm{R}$ combination restored chlorophyll biosynthesis of wheat seedlings initially grown under only $\mathrm{R}$ light.

However, earlier studies showed that $G$ light could inhibit the growth of algae, fungi, plant cell cultures and some higher plants [32-35]. Herein, we also observed that G light inhibited the growth of lettuce. Plant height; stem diameter, leaf thickness, and fresh weight above ground. SPAD value and number of leaves significantly decreased under G LED light compare with the other LED light treatments. Stem diameter and fresh weight above ground were particularly affected by $\mathrm{G}$ LED light, characteristics which dictate lettuce yield. However, anthocyanin content was significantly increased under G LED lights compared with the other light treatments.

Kim et al. [36] found that plants grown under $24 \%$ G LED light had greater fresh mass, dry mass and leaf area than plants grown under combinations of $B: R$ and $B: G: R$ in lettuce. Furthermore they found that $24 \% \mathrm{G}$ increased lettuce growth, and more than $50 \% \mathrm{G}$ inhibited plant growth [37]. Here, we found that lettuce quality characteristics were better under R:B combination than under monochromatic G, R, B, P and Y; in particular, the quality characteristics of lettuce grown under $\mathrm{R} / \mathrm{B}(4 / 1)$ was better that under other lights.

Furthermore, many studies have reported that the combination of $\mathrm{R}$ and $\mathrm{B}$ lights plays important role in leaf expansion and biomass accumulation [38-41]. Wang et al. [2] studied leaf morphology and shoot dry weight grown under different combinations of $\mathrm{R} / \mathrm{B}$ light ratios, including $12,8,4$, and 1 . The authors found that shoot dry weight increased with increasing $\mathrm{R} / \mathrm{B}$ light ratio and was mainly due to an increase in leaf number and leaf area.

Herein, fresh weight above ground of lettuce grown under R/B combinations significantly increased compared with that of $G$ and $\mathrm{Y}$; while other LED light treatments resulted in no difference. Moreover, the vitamin $\mathrm{C}$, soluble sugar, soluble protein and GDH significantly increased under R/B (9/1) and $\mathrm{R} / \mathrm{B}(4 / 1)$ combinations compared with lettuce grown under $\mathrm{W}$ light [42]. These parameters were especially high when grown under R/B (4/1), indicating this combination can efficiently contribute to increased quality characteristics in lettuce.

\section{Acknowledgement}

This work was supported by the China Agriculture Research System [grant number CARS-25-C-06].

\section{Conflict of Interest}

All authors contributed equally and declare that there are no conflicts of interest.

\section{References}

1. Mc Donald MS. Photobiology of Higher Plants. John Wiley \& Sons Ltd., West Sussex, England. 2003.

2. Wang J, Lu W, Tong $\mathrm{Y}$, et al. Leaf Morphology, Photosynthetic Performance, Chlorophyll Fluorescence, Stomatal Development of Lettuce (Lactuca sativa L.) Exposed to Different Ratios of Red Light to Blue Light. Front Plant Sci. 2016;7:250.

3. Acock E, Charkes-Edwards DA, Fitter DJ, et al. The contribution of leaves from different levels within a tomato crop to canopy net photosynthesis: an experimental examination of two canopy models. J Exp Bot. 1971;29:815-27. 
Citation: Zhiqiang S, Tao Z, Yuanyuan S, et al. The effect of different spectral LED lights on the phenotypic and physiological characteristics of lettuce (Lactuca sativa) at picking stage. J Biochem Biotech. 2017;1(1):14-19.

4. Corré NC. Growth and morphogenesis of sun and shade plants. I. The influence of light intensity. Acta Bot. Neerlandica. 1983;32:49-62.

5. Pimputkar S, Speck JS, DenBaars SP, et al. Prospects for LED lighting. Nat Photon. 2009;3:180-2.

6. Johkan M, Shoji K, Goto F, et al. Blue light emitting diode light irradiation of seedlings improves seedling quality and growth after transplanting in red leaf lettuce. Hortic Sci. 2010;45:1809-14.

7. Liu XY, Chang TT, Guo SR, et al. Effect of diferent light quality of LED on growth and photosynthetic cheracter in cherry tomato seedling. Acta Hortic. 2011;907:325-30.

8. Cope KR, Snowden MC, Bugbee B. Photobiological interactions of blue light and photosynthetic photon flux: effects of monochromatic and broad-spectrum light sources. Photochem Photobiol. 2014;90:574-84.

9. Lin KH, Huang MY, Huang WD, et al. The effects of red, blue, and white light-emitting diodes on the growth, development, and edible quality of hydroponically grown lettuce (Lactuca sativa L. var. capitata). Sci Hortil. 2013;50:86-91.

10. Hoenecke ME, Bula RJ, Tibbitts TW. Importance of 'blue' photon levels for lettuce seedlings grown under red-lightemitting diodes. HortScience. 1992;27:427-30.

11. Wojciechowska R, Długosz-Grochowska O, Kołton A, et al. Effects of LED supplemental lighting on yield and some quality parameters of lamb's lettuce grown in two winter cycles. Sci Hortic. 2015;187:80-6.

12. Ohashi-Kaneko K, Takase M, Kon N, et al. Effect of light quality on growth and vegetable quality in leaf lettuce, spinach and komatsuna. Environ Control Biol, 2007;45:189-98.

13. Son KH, Oh MM. Leaf shape, growth, and antioxidant phenolic compounds of two lettuce cultivars grown under various combinations of blue and red light-emitting diodes. HortScience. 2013;48:988-95.

14. Wollaeger HM, Runkle ES. Growth of impatiens, petunia, salvia, and tomato seedlings under blue, green, and red light-emitting diodes. HortScience. 2014;49:734-40.

15. Han $\mathrm{T}$, Vaganov $\mathrm{V}$, Cao $\mathrm{S}$, et al. Improving "color rendering" of LED lighting for the growth of lettuce. Sci Rep. 2017;7:45944.

16. Bhattacharjee C, Saxena VK, Dutta S. Watermelon juice concentration using ultrafiltration: Analysis of sugar and ascorbic acid. Food Sci Technol Int. 2017;10:72.

17. Chou SU, Boo HO, Heo BG, et al. Anthocyanin content and the activities of polyphenol oxidase, peroxidase and phenylalanine ammonia-lyase in lettuce cultivars. Int $\mathrm{J}$ Food Sci Nutr. 2012;63:45-8.

18. Zhan L, Hu J, Ai Z, et al. Light exposure during storage preserving soluble sugar and 1-ascorbic acid content of minimally processed romaine lettuce (Lactuca sativa L.var. longifolia). Food Chem 2013;136:273-8.

19. Cosgrove DJ. Photomodulation of growth. - In: Kendrick R.E. 1993.

20. Hogewoning SW, Trouwborst G, Maljaars H, et al. Blue light dose-responses of leaf photosynthesis, morphology, and chemical composition of Cucumis sativus grown under different combinations of red and blue light. J Exp Bot. 2010;61:3107-17.

21. Nhut DT, Takamura T, Watanabe H, et al. Responses of strawberry plantlets cultured in vitro under super bright red and blue light-emitting diodes (LEDs). Plant Cell Tissue Organ Cult. 2003;73:43-52.

22. Li H, Tang $\mathrm{C}, \mathrm{Xu} \mathrm{Z}$. The effects of different light qualities on rapeseed (Brassica napus L.) plantlet growth and morphogenesis in vitro. Sci Hortic. 2013;150:117-24.

23. Hernández R, Kubota $C$. Physiological responses of cucumber seedlings under different blue and red photon flux ratios using LEDs. Environ Exp Bot. 2016;121:66-74.

24. Wang C, Chen D, Chen M, et al. Stimulatory effects of blue light on the growth, monascin and ankaflavin production in Monascus. Biotechnol Lett. 2015;37:1043-8.

25. Nanya K, Ishigami Y, Hikosaka S, et al. Effects of blue and red light on stem elongation and flowering of tomato seedlings. Acta Hortic. 2012;956: 264-6.

26. Oh-Hama T, Hase E. Role of light in 5-aminolevulinic acid formation in wild strain and mutant $\mathrm{C}-2 \mathrm{~A}$ cells of Scenedesmus obliquus. Plant Cell Physiol. 1981;22:747-58.

27. Vesk M, Jeffrey SW. Effect of blue-green light on photosynthetic pigments and chloroplast structure in unicellular marine algae form six classes. J Phycol. 1977;13:280-8.

28. Jeffrey SW. Responses to light in aquatic plants. In: Pirson, A., Zimmermann, M.H. (Eds.), Encyclopedia of Planta Physiology. Springer, Verlag, Berlin. 1980.

29. Jeffrey SW, Vesk M. Blue-green light efects in marine microalgae: enhanced thylakoid and chlorophyll synthesis. In: Akoyunoglou, G. (Ed.), Photosynthesis VI Photosynthesis and Productivity. Balaban, Philadelphia, PA. 1981:435-42.

30. Leong TY, Goodchild DJ, Anderson JM. Effect of Light Quality on the Composition, Function, and Structure of Photosynthetic Thylakoid Membranes of Asplenium australasicum (Sm.) Hook. Plant Physiol. 1985;78:561-7.

31. Senger H, Bauer B. The influence of light quality on adaptation and function of the photosynthetic apparatus. $\mathrm{J}$ Photochem Photobiol. 1987;45:939-46.

32. Wang Y, Folta KM. Contributions of green light to plant growth and development. Am J Bot. 2013;100:70-8.

33. Tripathy $\mathrm{BC}$, Brown CS. Root-shoot interaction in the greening of wheat seedlings grown under red light. Plant Physiol. 1995; 107:407-11.

34. Klein RM. Repression of tissue cultutre growth by visible and near visible radiation. Plant Physiol. 1964;39:536-9.

35. Klein RM, Edsall PC, Gentile AC. Effects of near ultraviolet and green radiations on plant growth. Plant Physiol. 1965;40: 903-6.

36. Kim HH, Goins GD, Wheeler RM, et al. Green-light supplmentation for enhanced lettuce growth under red and blue light emitting diodes. Hort Sci. 2004;7:1622-71.

37. Kim HH, Wheeler RM, Sager JC, et al. Evaluation of lettuce growth using supplmental green light with red and 
blue light-emitting diodes in a controlled enviroment - a review of research at Kennedy Space Center. Acta Hortic. 2006;711:111-9.

38. Johkan M, Shoji K, Goto F, et al. Blue light-emitting diode light irradiation of seedlings improves seedling quality and growth after transplanting in red leaf lettuce. Hort Sci. 2010;45:1809-14.

39. Chang SX, Li CX, Yao XY, et al. Morphological, Photosynthetic, and Physiological Responses of Rapeseed Leaf to Different Combinations of Red and Blue Lights at the Rosette Stage. Front Plant Sci. 2016;7:1144.

40. Kronenberg GHM. Photomorphogenesis in plants, 2nd edition. - Dordrecht, The Netherlands, Kluwer Academic Publishers, 631-58.

41. Stutte GW, EdneyS, Skerritt T. Photoregulation of bioprotectant content of red leaf lettuce with light-emitting diodes. Hort Sci. 2009;44:79-82.
42. Yorio NC, Goins GD, Kagie HR, et al. Improving spinach, radish, and lettuce growth under red light-emitting diodes (LEDs) with blue light supplementation. Hort Sci. 2001;36:380-3.

\section{*Correspondence to}

Dr. Zhiqiang Sun,

College of Horticulture,

Henan Agricultural University,

Zhengzhou 450002, China

E-mail: Sunzhiqiang1956@sina.com 